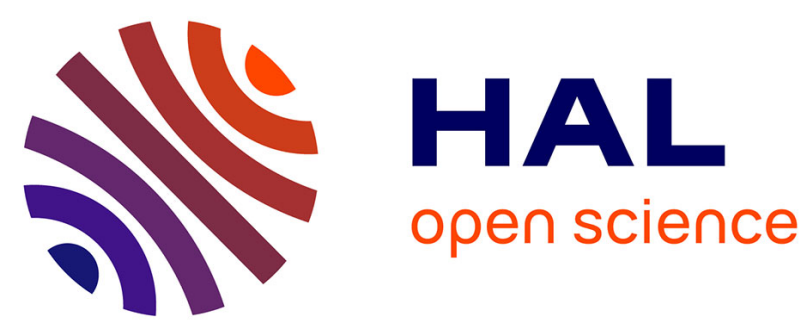

\title{
Simultaneous Records of Current and 380-km Distant Electric Field of a Bipolar Lightning Flash
}

Amirhossein Mostajabi, Mohammad Azadifar, Farhad Rachidi, Marcos

Rubinstein, Gerhard Diendorfer, Wolfgang Schulz, Hannes Pichler, Vladimir

A Rakov, Mario Paolone, Davide Pavanello

\section{To cite this version:}

Amirhossein Mostajabi, Mohammad Azadifar, Farhad Rachidi, Marcos Rubinstein, Gerhard Diendorfer, et al.. Simultaneous Records of Current and 380-km Distant Electric Field of a Bipolar Lightning Flash. 2017 International Symposium on Lightning Protection (XIV SIPDA), Oct 2017, Natal, Brazil. pp.2 - 6, 10.1109/sipda.2017.8116921 . hal-01791539

\section{HAL Id: hal-01791539 \\ https://hal.science/hal-01791539}

Submitted on 14 May 2018

HAL is a multi-disciplinary open access archive for the deposit and dissemination of scientific research documents, whether they are published or not. The documents may come from teaching and research institutions in France or abroad, or from public or private research centers.
L'archive ouverte pluridisciplinaire HAL, est destinée au dépôt et à la diffusion de documents scientifiques de niveau recherche, publiés ou non, émanant des établissements d'enseignement et de recherche français ou étrangers, des laboratoires publics ou privés. 


\title{
Simultaneous Records of Current and 380-km Distant Electric Field of a Bipolar Lightning Flash
}

\author{
Amirhossein Mostajabi ${ }^{1}$, Mohammad Azadifar ${ }^{1}$, Farhad Rachidi $^{1}$, Marcos Rubinstein ${ }^{2}$, Gerhard Diendorfer ${ }^{3}$, \\ Wolfgang Schulz ${ }^{3}$, Hannes Pichler ${ }^{3}$, Vladimir A. Rakov ${ }^{4,5}$, Mario Paolone ${ }^{6}$, Davide Pavanello ${ }^{7}$ \\ 1 Electromagnetic Compatibility Laboratory, Swiss Federal Institute of Technology (EPFL), 1015 Lausanne, Switzerland \\ 2 University of Applied Sciences of Western Switzerland (HES-SO), 1400 Yverdon-les-Bains, Switzerland \\ 3 OVE Service GmbH, Dept. ALDIS, Vienna, Austria \\ 4 Department of Electrical and Computer Engineering, University of Florida, Florida, USA \\ 5 Institute of Applied Physics, Russian Academy of Sciences, Nizhny Novgorod, Russia \\ 6 Distributed Energy Systems Laboratory, Swiss Federal Institute of Technology (EPFL), 1015 Lausanne, Switzerland \\ 7 University of Applied Sciences of Western Switzerland (HES-SO), 1950 Sion, Switzerland
}

\begin{abstract}
In this paper, we present and discuss simultaneous records of current and wideband electric field waveforms at 380 $\mathrm{km}$ distance from the strike point associated with an upward bipolar flash initiated from the Säntis Tower. The flash contains 23 negative strokes and one positive stroke. The height of the ionospheric reflection for the positive pulse was inferred to be about $94.9 \mathrm{~km}$, a value which is significantly higher than for negative pulses of this same flash, which range from 73 to $81 \mathrm{~km}$. It is also found that the ratio of the peak field to the current peak is about two times smaller for the positive pulse compared to negative pulses. This difference can be attributed to a lower return stroke speed for the positive stroke compared to that for negative strokes, and also to the fact that the enhancement of the electric field due to the presence of the tower and the mountain might be more significant for negative pulses, which are characterized by faster risetimes, than for the positive pulse.
\end{abstract}

Keywords-Bipolar lightning flash, simultaneous current and field measurement, ionospheric reflection, field-to-current conversion factor

\section{INTRODUCTION}

In a bipolar flash, the current waveform exhibits a polarity reversal, corresponding to a charge transfer to ground of both negative and positive polarities [1], [2]. Bipolar flashes are usually initiated by upward leaders from tall structures, but they can also be downward flashes [3].

About 3\% of the flashes recorded at the Säntis Tower are bipolar [4]. Fig. 1 shows the monthly distribution of negative, positive and bipolar lightning flashes accumulated over the period ranging from June 2010 to July 2016. It can be seen that positive and bipolar flashes occurred mostly during the warmer seasons (May to October).

Current waveforms associated with bipolar flashes were first reported by McEachron from his studies at the Empire State Building [5]. Further studies on bipolar lightning are based either on lightning current observations (e.g., [6], [7], [4]), or electromagnetic fields, sometimes with high-speed video observations (e.g., [8]-[11]). Only rarely have observations been reported that include simultaneous records of currents and fields (e.g., [12]-[14]).

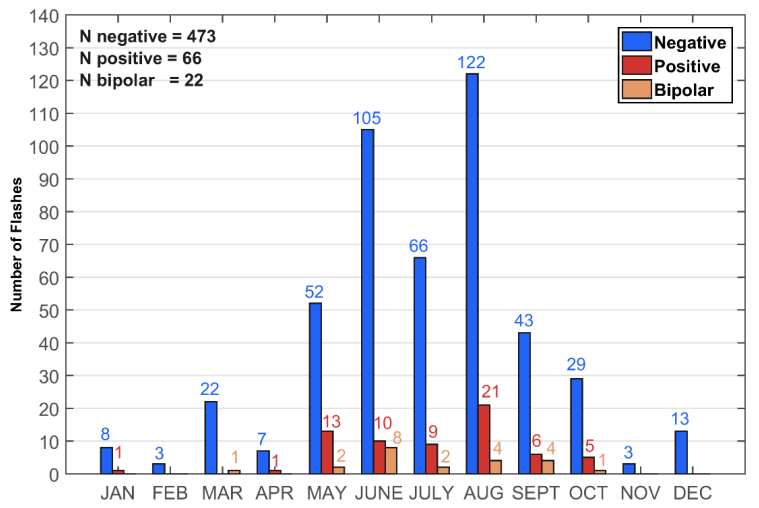

Fig. 1. Monthly distribution of negative, positive and bipolar lightning flashes recorded at Säntis Tower over the period ranging from June 2010 to July 2016.

In this paper, we present and discuss simultaneous records of current and wideband electric field waveforms at a $380 \mathrm{~km}$ distance from the strike point associated with an upward bipolar flash initiated from the Säntis Tower. The flash was recorded on September 21, 2014 and it contained 23 negative strokes and one positive pulse superimposed on the initial-stage current and belongs to the category I bipolar flashes according to the classification proposed by Rakov [15]. In this paper, we will treat the positive pulse as a stroke.

The rest of this paper is organized as follows. Section II briefly reviews the instrumentation installed at the Säntis Tower, Switzerland and the electric field measurement station in Neudorf, Austria. A brief description of the obtained data is presented in Section III. The analysis and discussion of the 
results are given in Section IV. Finally, conclusions are presented in Section V.

\section{EXPERIMENTAL SETUP AND INSTRUMENTATION}

\section{A. Current Measurement System at the Säntis Tower}

The 124-m tall Säntis Tower has been instrumented since May 2010 using advanced equipment including remote monitoring and control capabilities for accurate measurement of lightning current parameters enabling a high-resolution sampling of lightning currents over long observation windows [16], [3]. The analog outputs of the sensors are relayed to a digitizing system by means of optical fiber links. The system allows over-the-Internet remote maintenance, monitoring, and control.

A PXI platform with a current sampling rate of $50 \mathrm{MS} / \mathrm{s}$ is used to digitize and record measured waveforms. The lightning current is recorded over a 2.4-s time with a pretrigger delay of $960 \mathrm{~ms}$.

In 2013-2014, a certain number of updates were made to the overall measuring system. More details on the measurement sensors and instrumentation system can be found in [3], [16][19].

\section{B. Electric Field Measurement System}

Vertical electric fields were measured at a distance of 380 $\mathrm{km}$ from the tower (in Neudorf, Northern Austria) by way of a flat-plate antenna and digitized with a sampling rate of $5 \mathrm{MS} / \mathrm{s}$ [20]. The antenna was installed on the roof of a building with an estimated enhancement factor of about 2.5 [20]. The measured field values were corrected to account for this enhancement. The integrator decay time constant was $0.5 \mathrm{~ms}$, corresponding to a lower cutoff frequency of about $300 \mathrm{~Hz}$. The triggering signal was relayed to the field measurement station using TCP/IP over the Internet from the Säntis tower. The locations of the Säntis Tower and the field measuring station in Neudorf are shown in Fig. 2. More information on the electric field measurement system in Neudorf can be found in [20].

\section{OBTAINED DATA}

We present here an upward bipolar lightning flash recorded on September 21, 2014 at 15:14:09 (local time) along with its associated vertical electric fields in Neudorf, at $380 \mathrm{~km}$ from the Säntis Tower.

Fig. 3a shows the overall current waveform which contains an Initial Continuous Current (ICC) of negative polarity which lasted for about $320 \mathrm{~ms}$ (from 880 to $1200 \mathrm{~ms}$ ) and included more than 20 superimposed pulses with peak values of about 0.6 to $6.1 \mathrm{kA}$. After this initial current of negative polarity, the flash exhibits a polarity reversal of the current during its initial stage, therefore belonging to category I according to the classification proposed by Rakov [15]. It is worth noting that this bipolar flash can also be classified as being of Category III which involves return strokes of opposite polarity, assuming that the positive pulse can be treated as a stroke (which we do in this paper). The positive stroke is characterized by a peak current of $39.6 \mathrm{kA}$ and a risetime of $31 \mu \mathrm{s}$. An expanded view of the initial stage of the current in which the ICC is resolved is shown in the inset of the figure.
The associated vertical electric field of this flash is shown in Fig. 3b.

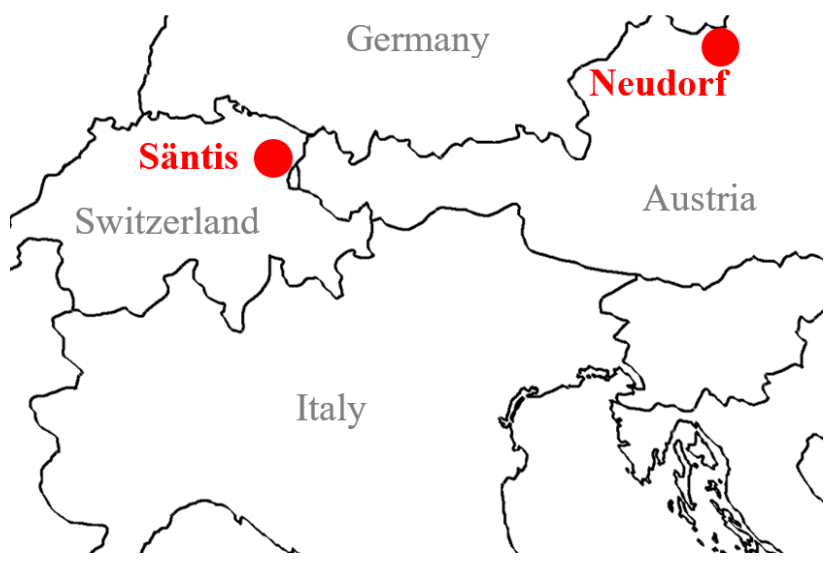

Fig. 2. The locationa of the Säntis Tower (Switzerland) and the electric field measurement station at Neudorf, Austria. The distance between Neudorf and the Säntis is $380 \mathrm{~km}$.

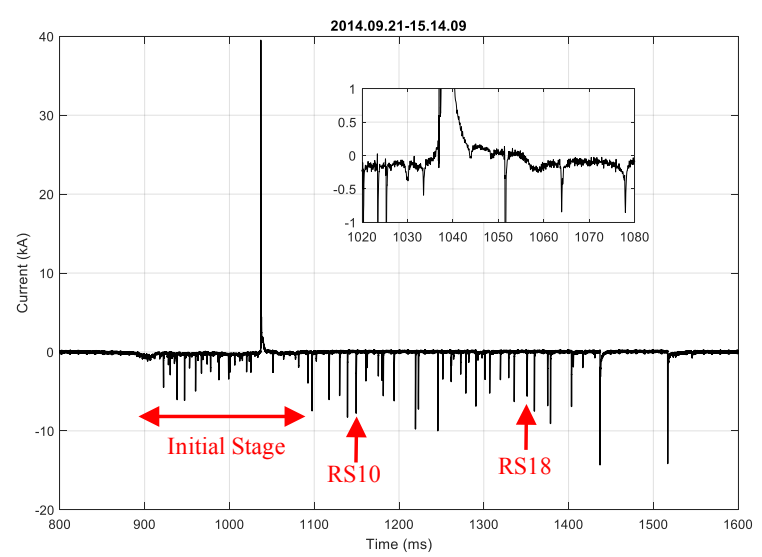

(a)

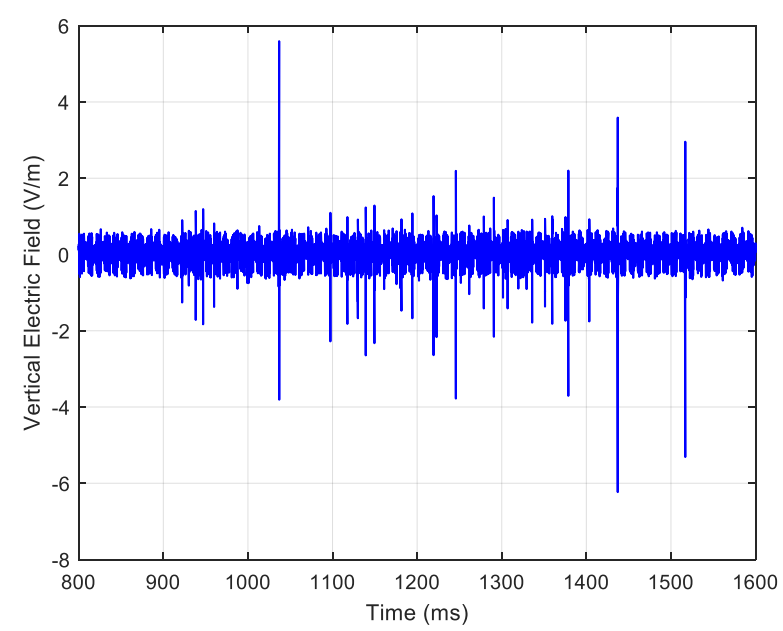

(b)

Fig. 3. Simultaneous current (a) and E-field (b) waveforms associated with a bipolar flash of category I that occurred on 21 September 2014, 15:14:09. The initial stage interval and two of the return strokes are shown in red. 


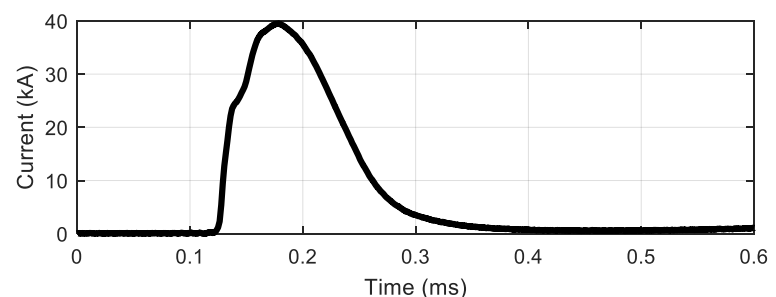

(a)

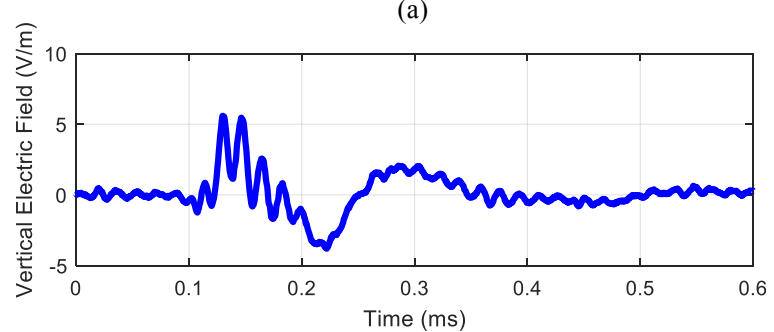

(b)

Fig. 4. Simultaneous current (a) and E-field (b) waveforms associated with the positive pulse of the bipolar flash of 21 September 2014, 15:14:09.

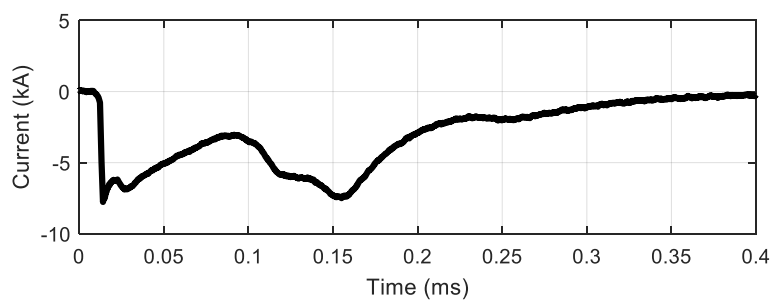

(a)

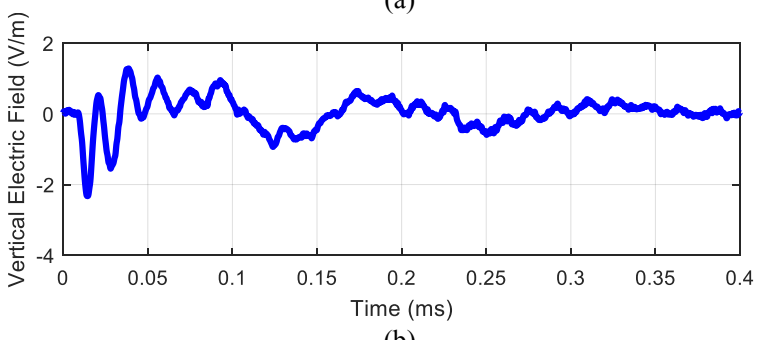

(b)

Fig. 5. Simultaneous current (a) and E-field (b) waveforms associated with a negative return stroke (labeled RS10 in Fig. 3a) of the bipolar flash of 21 September 2014, 15:14:09.

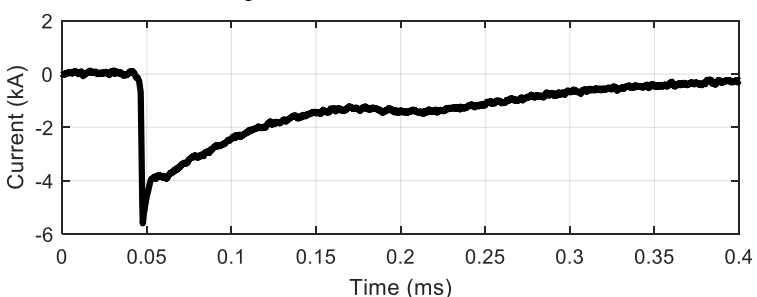

(a)

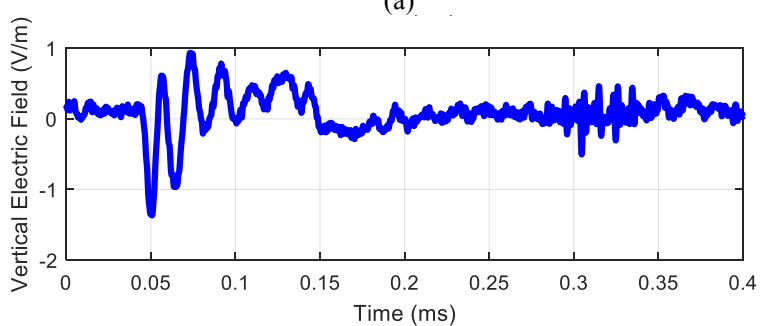

(b)

Fig. 6. Simultaneous current (a) and E-field (b) waveforms associated with a negative return stroke (labeled RS18 in Fig. 3a) of the bipolar flash of 21 September 2014, 15:14:09.
It should be noted that our field measuring system exhibited a high noise level at frequencies of 200, 300, 400 and $500 \mathrm{kHz}$. In order to reduce the noise, $20-\mathrm{kHz}$ bandwidth notch filters centered at each of the above-mentioned frequencies were applied to all recorded signals.

\section{ANAlysis of Individual Positive AND NeGatiVE PULSES}

\section{A. Simultaneous Current and Electric Field Waveforms}

Fig. 4 presents the plots of the individual waveforms of current and electric field associated with the positive pulse of the bipolar flash. Fig. 5 and 6 present similar plots for two negative return strokes of the same flash.

As discussed in [21], a $60-\mathrm{kHz}$ ringing can be seen in all the measured E-field waveforms. This effect might be due to the cable-car grounding wires of about $2.3 \mathrm{~km}$ in length connecting the Säntis Tower to the mountain base, which could form a halfwave resonator at that frequency [21].

\section{B. Ionospheric Reflections}

Using the zero-to-zero approach [22], one can infer the height of the reflection for the positive pulse to be about $94 \mathrm{~km}$. It should be noted that this flash occurred during daytime when the average height of reflection should be about $77 \mathrm{~km}$.

This flash contains numerous other negative pulses, both before and after the positive one. Fig. 7 shows, sequentially, the evaluated reflection heights for pulses of this flash that exhibited ionospheric reflections. As it can be seen, the reflection height of the positive pulse $(94.9 \mathrm{~km})$ is significantly higher than those for negative ICC pulses and return strokes in this flash, which range from 73 to $81 \mathrm{~km}$.

Changes of ionospheric reflection height for first and subsequent return strokes in downward flashes were reported in [22], [23]. They also observed that the reflection height tends to increase with increasing return-stroke peak current. Azadifar et al. [21], in their analysis of negative upward flashes initiated from the Säntis Tower, did not observe any significant variation of the reflection height as a function of stroke order within a flash. As discussed in [21], this might be due to the fact that the peak currents in their recorded upward flashes were much smaller than the downward flashes studied by Somu et al. [23].

In our dataset (see Fig. 7), the reflection height inferred for negative strokes before and after the positive pulse assumes very similar values, while the estimated reflection height for the positive pulse is significantly higher. This is to some extent consistent with the analysis of [22], [23], given that the return stroke current peaks for negative strokes range from 2.9 to 13.2 $\mathrm{kA}$, while the positive pulse peak is about $40 \mathrm{kA}$. More data and further analyses are needed to understand the dependence of the reflection height on the source characteristics (return stroke current peak, frequency content, polarity, channel geometry, etc.).

\section{Field-to-Current Conversion Factor}

Fig. 8 shows a scatterplot of electric field peak versus current peak for all the 24 detected pulses. Negative pulses are shown in blue and the measured positive one is shown in red in 
this figure. The best fit linear regression (forced to go through the origin of coordinates) is also shown in Fig. 8.

It can be seen that the ratio of the peak field to the current peak is much smaller (factor of about 2.3) for the positive pulse compared to negative pulses. Among reasons that could explain this difference are:

- The return stroke speed for positive strokes is, in general, smaller than that for negative strokes [24]-[26];

- The enhancement of the electric field due to the presence of the tower and the mountain [27]-[31] might be more significant for negative pulses, which are characterized by faster risetimes, than for positive pulses.

A recent full wave theoretical analysis of the propagation effects of lightning electromagnetic fields over mountainous terrain [31], supported by experimental observations consisting of simultaneous records of lightning currents and electric fields associated with upward negative lightning flashes to the instrumented Säntis Tower revealed that the combined effect of the tower and the mountainous terrain topography around the Säntis Tower results in an enhancement of the radiated electric field from negative return strokes. Further full-wave analysis is needed to investigate the effect of these factors on the propagation of radiated electromagnetic fields associated with positive return strokes.

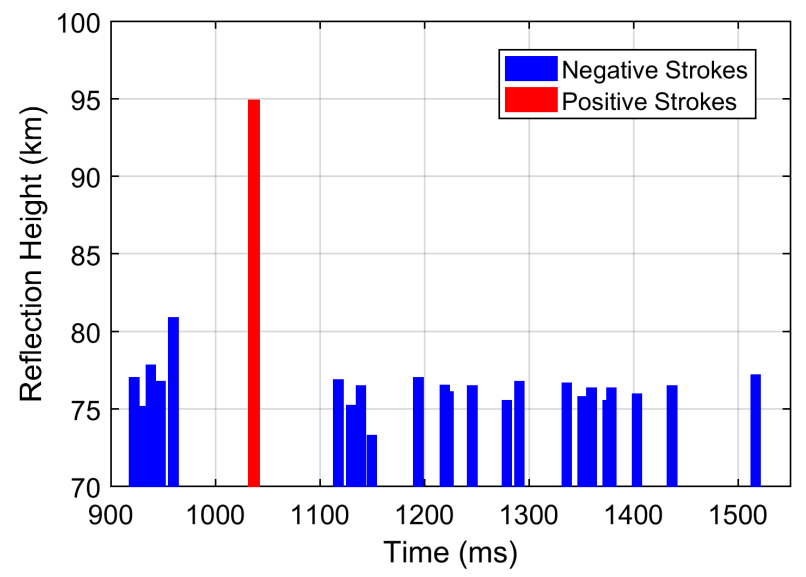

Fig. 7. Sequence of evaluated reflection heights for the negative pulses (in red) and the positive pulse (in blue) of the flash of 21 September 2014, 15:14:09.

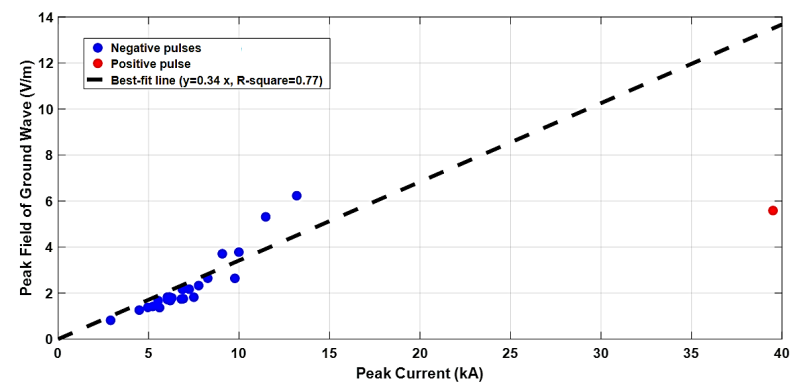

Fig. 8. Electric field peak of the ground wave at $380 \mathrm{~km}$ versus current peak for all the pulses of the flash of 21 September 2014, 15:14:09. The positive pulse is shown in red and 23 negative pulses are shown in blue. The best fit linear regression is also shown in the figure.

\section{CONCLUSION}

We presented and discussed simultaneous records of current and wideband electric field waveforms at $380 \mathrm{~km}$ distance from the strike point associated with a bipolar upward flash initiated from the Säntis Tower. The recorded flash contains 23 negative and one positive strokes.

The height of the ionospheric reflection for the positive pulse was inferred to be about $94.9 \mathrm{~km}$, a value which is significantly higher than for negative pulses of this same flash, which range from 73.3 to $80.9 \mathrm{~km}$.

It is also found that the ratio of the peak field to the current peak is about two times smaller for the positive pulse compared to negative pulses. This difference can be attributed to a lower return stroke speed for the positive stroke, compared to the negative strokes, and also to the fact that the enhancement of the electric field due to the presence of the tower and the mountain might be more significant for negative pulses, which are characterized by faster risetimes, than for the positive pulse.

\section{ACKNOWLEDGMENT}

Financial supports from the Swiss National Science Foundation (Project No. 200021_147058) and the European Union's Horizon 2020 research and innovation programme (grant agreement. No 737033-LLR) are acknowledged.

\section{REFERENCES}

[1] M. Azadifar et al. "An update on the charaterictics of positive flashes recorded on the Säntis Tower," 2014 International Conference on Lightning Protection (ICLP). pp. 777-781, 2014.

[2] C. Romero, M. Rubinstein, F. Rachidi, M. Paolone, V. A. Rakov, and D. Pavanello, "Some characteristics of positive and bipolar lightning flashes recorded on the Säntis tower in 2010 and 2011," 2012 International Conference on Lightning Protection (ICLP). pp. 1-5, 2012.

[3] M. Azadifar, M. Paolone, D. Pavanello, F. Rachidi, C. Romero, and M. Rubinstein, "An Update on the Instrumentation of the Säntis Tower in Switzerland for Lightning Current Measurements and Obtained Results," in CIGRE Int. Colloquium on Lightning and Power Systems, 2014.

[4] M. Azadifar, F. Rachidi, M. Rubinstein, V. A. Rakov, M. Paolone, and D. Pavanello, "Bipolar lightning flashes observed at the Säntis Tower: Do we need to modify the traditional classification?," Journal of Geophysical Research: Atmospheres, vol. 121, no. 23, p. 14,117-14,126, 2016.

[5] K. B. McEachron, "Lightning to the empire state building," Journal of the Franklin Institute, vol. 227, no. 2, pp. 149-217, 1939.

[6] K. Narita, Y. Goto, H. Komuro, and S. Sawada, "Bipolar lightning in winter at Maki, Japan," Journal of Geophysical Research: Atmospheres, vol. 94, no. D11, pp. 13191-13195, Sep. 1989.

[7] W. Schulz and G. Diendorfer, "Bipolar flashes detected with lightning location systems and measured on an instrumented tower," in Proceedings of the VII International Symposium on Lightning Protection, 2003, pp. 6 9.

[8] M. Miki, A. Wada, and A. Asakawa, "Observation of upward lightning in winter at the coast of Japan Sea with a high-speed video camera," in Proc. 27th Int. Conf. Lightning Protection, 1a2, 2004, pp. 63-67.

[9] M. M. F. Saba, C. Schumann, T. A. Warner, J. H. Helsdon, W. Schulz, and R. E. Orville, "Bipolar cloud-to-ground lightning flash observations," Journal of Geophysical Research: Atmospheres, vol. 118, no. 19, p. 11,098-11,106, Oct. 2013.

[10] A. C. V Saraiva et al., "High-speed video and electromagnetic analysis of two natural bipolar cloud-to-ground lightning flashes," Journal of Geophysical Research: Atmospheres, vol. 119, no. 10, pp. 6105-6127, May 2014.

[11] H. Zhou, G. Diendorfer, R. Thottappillil, H. Pichler, and M. Mair, "Characteristics of upward bipolar lightning flashes observed at the 
Gaisberg Tower," Journal of Geophysical Research, vol. 116, no. D13, p. D13106, Jul. 2011.

[12] F. Heidler, W. Zischank, and J. Wiesinger, "Statistics of lightning current parameters and related nearby magnetic fields measured at the Peissenberg tower," in Proc. 25th Int. Conf. on Lightning Protection, Rhodes, Greece, 2000, pp. 78-83.

[13] J. Jerauld, M. A. Uman, V. A. Rakov, K. J. Rambo, and D. M. Jordan, "A triggered lightning flash containing both negative and positive strokes," Geophysical Research Letters, vol. 31, no. 8, p. n/a-n/a, Apr. 2004.

[14] D. Wang and N. Takagi, "Characteristics of upward bipolar lightning derived from simultaneous recording of electric current and electric field change," Proc. of URSI E, vol. 6, p. 2, 2008.

[15] V. A. Rakov, "A Review of Positive and Bipolar Lightning Discharges," Bulletin of the American Meteorological Society, vol. 84, no. 6, pp. 767776, Jun. 2003.

[16] C. Romero et al., "A system for the measurements of lightning currents at the Säntis Tower," Electric Power Systems Research, vol. 82, no. 1, pp. 34-43, 2012.

[17] C. Romero, F. Rachidi, M. Paolone, and S. Member, "Statistical Distributions of Lightning Currents Associated With Upward Negative Flashes Based on the Data Collected at the Säntis ( EMC) Tower in 2010 and 2011," IEEE Transaction on Power Delivery, vol. 28, no. 3, pp. 18041812,2013

[18] C. Romero, A. Mediano, A. Rubinstein, F. Rachidi, A. Rubinstein, and M. Paolone, "Measurement of Lightning Currents Using a Combination of Rogowski Coils and B-Dot Sensors," Journal of Lightning Research, vol. 4, pp. 71-77, 2012.

[19] C. Romero, F. Rachidi, R. M., P. M., R. V. A., and D. Pavanello, "Positive Lightning Flashes Recorded on the Säntis Tower in 2010 and 2011," Journal of Geophysical Research, p. 12'879-12'892, 2013.

[20] H. Pichler, G. Diendorfer, and M. Mair, "Some Parameters of Correlated Current and Radiated Field Pulses from Lightning to the Gaisberg Tower," IEEE Transactions on Electrical and Electronic Engineering, pp. 8-13, 2010.

[21] M. Azadifar et al., "Analysis of lightning-ionosphere interaction using simultaneous records of source current and $380 \mathrm{~km}$ distant electric field," Journal of Atmospheric and Solar-Terrestrial Physics, vol. 159, pp. 48-
56, Jun. 2017.

[22] M. A. Haddad, V. A. Rakov, and S. A. Cummer, "New measurements of lightning electric fields in Florida: Waveform characteristics, interaction with the ionosphere, and peak current estimates," Journal of Geophysical Research Atmospheres, vol. 117, no. 10, 2012.

[23] V. B. Somu, V. A. Rakov, M. A. Haddad, and S. A. Cummer, "A study of changes in apparent ionospheric reflection height within individual lightning flashes," Journal of Atmospheric and Solar-Terrestrial Physics, vol. 136, pp. 66-79, 2015.

[24] D. Wang, N. Takagi, T. Watanabe, V. A. Rakov, and M. A. Uman, "Observed leader and return-stroke propagation characteristics in the bottom $400 \mathrm{~m}$ of a rocket-triggered lightning channel," Journal of Geophysical Research: Atmospheres, vol. 104, no. D12, pp. 14369 14376, Jun. 1999.

[25] V. A. Rakov, "Lightning return stroke speed," J. Lightning Res, vol. 1, pp. 80-89, 2007.

[26] V. P. Idone, R. E. Orville, D. M. Mach, and W. D. Rust, "The propagation speed of a positive lightning return stroke," Geophysical research letters, vol. 14, no. 11, pp. 1150-1153, 1987.

[27] M. Azadifar et al., "Evaluation of the performance characteristics of the European Lightning Detection Network EUCLID in the Alps region for upward negative flashes using direct measurements at the instrumented Säntis Tower," Journal of Geophysical Research : Atmospheres, pp. 595 606, 2015.

[28] Y. Baba and V. A. Rakov, "Lightning electromagnetic environment in the presence of a tall grounded strike object," Journal of Geophysical Research: Atmospheres, vol. 110, no. D9, p. n/a-n/a, 2005.

[29] Y. Baba and V. A. Rakov, "Lightning strikes to tall objects: Currents inferred from far electromagnetic fields versus directly measured currents," Geophysical Research Letters, vol. 34, no. 19, p. n/a-n/a, 2007.

[30] J. L. Bermudez et al., "Far-field-current relationship based on the TL model for lightning return strokes to elevated strike objects," IEEE Transactions on Electromagnetic Compatibility, vol. 47, no. 1. pp. 146159, 2005.

[31] D. Li et al., "On Lightning Electromagnetic Field Propagation Along an Irregular Terrain," IEEE Transactions on Electromagnetic Compatibility, vol. 58, no. 1. pp. 161-171, 2016. 